\title{
Desenvolvimento Humano: Contribuições da PSICOLOGIA MORAL ${ }^{1}$
}

\author{
Yves de La Taille ${ }^{2}$ \\ Instituto de Psicologia - USP
}

\begin{abstract}
Procuramos avaliar as contribuições do conhecimento acumulado pela Psicologia Moral para a compreensão do desenvolvimento humano, para sustentar a tese segundo a qual a fonte energética do dever moral precisa ser procurada não só em sentimentos exclusivamente morais, mas também em sentimentos que desempenham um papel para o próprio desenvolvimento humano no seu conjunto. Três são os passos da análise deste artigo. Em primeiro lugar, verificar se há possibilidade de articulação entre teorias psicológicas que enfatizam a dimensão afetiva da moralidade (Freud e Durkheim) e outras que enfatizam a dimensão intelectual (Piaget e Kohlberg). Em segundo lugar, uma vez constatada a impossibilidade dessa articulação, sustentar que o sentimento de vergonha, presente na moralidade mas também em outras dimensões do desenvolvimento humano, é condição necessária ao sentimento de obrigatoriedade. Finalmente, analisar se tal sentimento é passível de ser evocado como fonte energética essencial nas abordagens que enfatizam a dimensão intelectual da moralidade.
\end{abstract}

Descritores: Moral. Desenvolvimento humano. Vergonha. Honra.

Drocurarei analisar aqui as possíveis contribuições da Psicologia Moral para a compreensão do desenvolvimento humano. O tema contém dois conceitos e um operador. Os conceitos são: 1) desenvolvimento humano, fórmula geral que remete a processos ontogenéticos, e, 2) Psicologia Moral, área clás-

1 Texto da aula proferida no dia 26 de junho de 2006, no concurso para o cargo de Professor Titular do Instituto de Psicologia da Universidade de São Paulo.

2 Docente do Instituto de Psicologia da Universidade de São Paulo. Endereço eletrônico: ytaille@uol.com.br 
sica da Psicologia, notadamente da Psicologia do Desenvolvimento, em que se estudam os processos psíquicos por meio dos quais se legitimam regras, princípios e valores morais, entendo-se por moral aquilo que é da ordem do dever. Quanto ao operador - contribuições -, ele indica uma relação entre moralidade e desenvolvimento humano e um enriquecimento dos conhecimentos sobre este último, em razão dos estudos da primeira.

Posto como pergunta: há contribuição da Psicologia Moral para o desenvolvimento humano? E, em caso de resposta afirmativa, quais?

A primeira pergunta (há contribuições?) não tem grande interesse, uma vez que o conhecimento da parte sempre enriquece o conhecimento do todo. Fixemos-nos, portanto, na segunda: quais? Como nos diz Gilles Deleuze (2004), uma pergunta pode ser interpretada como interrogação ou como problema. Segundo o filósofo francês, uma interrogação incide sobre opiniões e/ou sobre conhecimentos, e um problema implica a necessidade de resolução. Uma interpretação interrogativa da nossa pergunta equivaleria a perguntas do tipo: "que opinião temos sobre as contribuições da Psicologia Moral para o desenvolvimento humano?" ou "o que sabemos sobre tais contribuições?" Uma interpretação problemática traduzir-se-ia em perguntas diferentes. Por exemplo: "se houver contribuições da Psicologia Moral para o desenvolvimento humano, que diferença fazem? Por que queremos saber sobre tais contribuições? Quais quereríamos que houvesse?"

Opto pela interpretação problemática e anuncio o problema que servirá de fio condutor à minha fala: a fonte energética desse querer particular que é o dever.

Faço um pequeno comentário a respeito da relação querer/dever. Na linguagem natural, não raro se opõem os dois verbos. Como o dever remete à idéia de obrigação, pensa-se que, se alguém deve fazer alguma coisa, é porque não quer fazê-lo e que, se não houvesse a obrigação, faria outra coisa. Tal oposição entre querer e dever é válida se a obrigação decorrer de alguma fonte exterior de poder. Mas, como o dever moral pressupõe, para merecer esse nome, uma vontade livre de agir, portanto não coagida por forças exteriores a ela, é legítimo dizer que o dever é uma forma de querer. Todo o mistério consiste em saber qual é a fonte energética que enseja esse querer, qual é a fonte desse sentimento de obrigatoriedade que preside o dever. Eis o problema que pretendo equacionar. 


\section{Desenvolvimento Humano: Contribuições da Psicologia Moral}

Vejamos, agora, a hipótese que me servirá de guia para a análise: a fonte energética do dever precisa ser procurada não só em sentimentos exclusivamente morais, mas também em sentimentos que desempenham um papel para o próprio desenvolvimento humano.

Três são os passos que seguirei em minha análise. Em primeiro lugar, verificarei se há possibilidade de articulação entre teorias psicológicas que enfatizam a dimensão afetiva da moralidade e aquelas que enfatizam sua dimensão intelectual. Em segundo lugar, analisarei se o sentimento de vergonha, presente na moralidade mas também em outras dimensões do desenvolvimento humano, não seria condição necessária ao sentimento de obrigatoriedade. Finalmente, verificarei se tal sentimento é passível de ser evocado como fonte energética essencial nas abordagens que enfatizam a dimensão intelectual da moralidade.

\section{Teorias da dimensão intelectual e teorias da dimensão afetiva da moralidade}

Como se sabe, há teorias psicológicas da moralidade que enfatizam sua dimensão intelectual ou sua dimensão afetiva. As primeiras debruçam-se sobre o 'saber fazer', as últimas, sobre o "querer fazer". Como essas duas dimensões essenciais à moralidade já foram estudadas, pode-se procurar saber se as teorias que delas se ocuparam são articuláveis entre si. Mas articular teorias não significa "fundi-las" - o que seria impossível -, mas verificar se são compatíveis nas suas afirmações a respeito de conceitos centrais, incontornáveis, para o tema estudado. Dois conceitos parecem-me ter essa importância: a autonomia e o universalismo moral psicológico.

Começemos definindo a autonomia. Autonomia é um termo polissêmico. Para a moralidade, dois sentidos devem ser lembrados. O primeiro ligase à questão da liberdade: é autônomo quem goza de liberdade, seja porque suas ações não são decorrentes de uma forma de poder exterior ao sujeito, seja porque não é irremediavelmente determinado por forças internas sobre as quais a vontade não exerce influência alguma. Exemplos: uma pessoa coagida, sob ameaça de fuzilamento, a ir para a guerra, não é autônoma, como não são autônomos os animais, por terem suas ações determinadas pelo instinto, e 
não por sua consciência. Como ações devidas a alguma relação de poder não integram, como vimos, a moralidade, só nos interessa a relação energética/ consciência.

Se considerarmos que o fato de experimentar todo e qualquer sentimento não depende do poder da consciência, teríamos que a autonomia é inapelavelmente impossível. Mas assumir essa tese equivaleria a não distinguir forças afetivas que de fato se impõem à consciência - sem que esta as possa influenciar ou modificar - daquelas que sofrem uma ação reguladora da razão. No caso do instinto, por exemplo, temos uma força pouco ou nada regulada pela consciência, mas há sentimentos que admitem tal regulação. Tomemos o exemplo da simpatia, ou empatia, que Adam Smith (1999) definia como afinidade com toda paixão, e que os dicionários costumam definir como faculdade de compenetrar-se dos sentimentos alheios. Ora, é claro que a razão interfere na experiência dessa faculdade afetiva. Por exemplo, sentiremos simpatia por uma criança que chora porque deixou cair seu sorvete - a simpatia, no caso, chama-se compaixão - mas dificilmente experimentaremos o mesmo sentimento em relação a um adulto que chora pelo mesmo motivo. É o juízo que nos faz, no primeiro caso, experimentar compaixão: compreendemos e julgamos normal ou legítimo uma criança se desesperar por perder uma guloseima, e é também o juízo que, no segundo caso, causa nossa frieza, pois não achamos normal nem legítimo - achamos até patético - um adulto se desesperar pelo mesmo motivo. Todavia, sentiríamos compaixão, se soubéssemos que o adulto em questão sofre de alguma deficiência que o impede de ter uma reação de adulto normal. Em resumo, no caso da simpatia, o juízo exerce um papel e, portanto, quem a experimenta não está totalmente subjugado por uma força afetiva que não sofre regulação por parte da consciência. Nesses casos em que há alguma regulação, podemos falar em graus de liberdade - embora nunca absolutos - e, portanto, em autonomia (tampouco ela absoluta).

$\mathrm{O}$ segundo sentido de autonomia que nos interessa aqui refere-se à autoridade: é autônomo quem legitima regras, princípios e valores morais sem referência a uma fonte que o transcende, sem referência, portanto, a figuras ou instâncias de autoridade (Deus, por exemplo).

Em ambos os sentidos de autonomia de que falamos, a condição oposta é a heteronomia. 


\section{Desenvolvimento Humano: Contribuições da Psicologia Moral}

Quanto ao universalismo moral psicológico, ele consiste em afirmar que haveria no ser humano uma tendência a eleger determinados princípios morais em detrimento de outros (ideal de justiça, por exemplo). Esse universalismo se opõe ao relativismo moral, que também chamo de psicológico, para distingui-lo do relativismo axiológico, segundo o qual não é possível, do ponto de vista moral, decidir se um sistema é superior, e, portanto, preferível a outros. Não haveria uma "álgebra moral" capaz de hierarquizar bens. Trata-se de uma posição filosófica. O relativismo moral psicológico não implica abrir mão de hierarquizar sistemas morais, mas de afirmar que não há nada no homem que o faz preferir necessariamente um a outros. Existem vários sistemas, mas nenhum tenderia a se impor à consciência humana em razão de fatores psicológicos.

Assim, verifica-se que tanto a autonomia e quanto o universalismo são incontornáveis para a moralidade e, por conseguinte, para a Psicologia Moral. Vejamos, então, como são equacionados por algumas teorias da Psicologia Moral.

Comecemos por duas teorias que enfatizam a dimensão intelectual: as de Jean Piaget (1932) e Lawrence Kohlberg (1981). Podemos tratá-las conjuntamente porque, no que tange às questões da autonomia/heteronomia e do universalismo/relativismo morais psicológicos, sustentam as mesmas teses. Trata-se de duas teorias dedicadas à evolução do juízo moral, de influência inconteste na história da Psicologia Moral, e que são sustentadas por inúmeras pesquisas empíricas com crianças, adolescentes e adultos, realizadas nos quatro cantos do mundo. Como se sabe, Piaget e Kohlberg avaliam que os homens são capazes de experimentar esse querer particular que é o dever, mas que os juízos que os guiam, cognitivamente falando, passam por vários estágios de desenvolvimento. É justamente na descrição desses estágios que encontramos os temas da autonomia e do universalismo.

Comecemos pela autonomia. Após uma fase pré-moral, chamada anomia, a criança penetra o universo moral e é penetrada por ele: o primeiro estágio, para Piaget, e os primeiros estágios, para Kohlberg, correspondem a fases de heteronomia. Tal heteronomia não é definida por uma falta de liberdade (como vimos, uma das possibilidades de definição da heteronomia), mas pela necessidade de uma referência a instâncias de autoridade, para a legitimação 
do sistema moral adotado pelo sujeito. Mas essa heteronomia não é o destino inevitável da moralidade humana, pois ela poderá ser superada por uma fase de autonomia, cujos primeiros sinais Piaget identifica em crianças de 9 a 10 anos, e que Kohlberg afirma só se consolidar nos estágios que ele chama de pós-convencionais, atingidos por muito poucas pessoas, mas ainda assim um potencial ao alcance de todos.

Em resumo, para Piaget e Kohlberg, embora seja rara, a autonomia moral - definida como não necessidade de referência a figuras ou instâncias de autoridade - é uma realidade do universo moral.

Quanto ao universalismo moral psicológico, ele também é afirmado pelos dois autores, para quem o desenvolvimento moral segue um rumo identificável: o de conceber a moral como organizada em função do ideal de justiça (inspirado pela eqüidade) e da reciprocidade universal. Tal tese, não claramente expressa por Piaget, é defendida em alto e bom som por seu seguidor, Kohlberg. Para ambos, se é verdade que, em fase de heteronomia, o sujeito esposa qualquer sistema moral, contanto que defendido por instâncias de autoridade, é também verdade que, superada a dependência heteronômica, em fase de autonomia moral, portanto, certos ideais morais se impõem, e não outros. E tal imposição deriva de processos sociais de cooperação e de processos psíquicos individuais de auto-regulação.

Em resumo, Piaget e Kohlberg pensam ter identificado, entre as potencialidades do ser humano, uma tendência a legitimar um certo sistema moral em detrimento de outros. Portanto, para essas duas teorias da dimensão intelectual da moralidade, autonomia e universalismo são realidades.

Vejamos agora se tal diagnóstico é possível em outras teorias, que enfatizam a dimensão afetiva. Comecemos pela teoria de Freud

Como se sabe, diferentemente de Piaget e Kohlberg, Freud não se dedicou a pesquisas exclusivamente relacionadas à moralidade: suas teses a respeito derivam de suas observações clínicas e de seu sistema teórico. Note-se também que a maioria dos estudos que se encontram na área de Psicologia Moral pouco ou nada emprega da teoria psicanalítica. Tal fato se deve em parte à tradição anglo-saxônica que domina a área: fazem-se sobretudo estudos empíricos controlados estatisticamente, e pouco se empregam estudos de caso, 


\section{Desenvolvimento Humano: Contribuições da Psicologia Moral}

embora haja exceções, como é o caso de Carol Gilligan (1982), que estuda o que ela chama de ética do cuidado, que, segundo ela, distingue mulheres de homens. A ausência de referências à teoria de Freud também se deve à grande influência dos trabalhos de Kohlberg, cujo resultado é a ênfase na dimensão intelectual da moralidade.

Todavia, se pouco se fala da abordagem freudiana entre os pesquisadores da Psicologia Moral, muito se fala dela em outras áreas da Psicologia, e é interessante que, quando filósofos da moralidade falam de estudos psicológicos - o que é raro -, quase sempre citam a teoria psicanalítica freudiana, e quase nunca outras abordagens - com exceção de Habermas (1986), Rawls (1971) e Flanagan (1996), que se referem explicitamente aos estudos de Piaget e Kohlberg.

Isto posto, sabe-se que Freud, assim como Piaget e Kohlberg, reconhece a realidade deste querer singular que é o dever. No seu texto $O$ ego e o id (Freud, 1923/1991), ele chega a comparar a força afetiva que preside o dever ao imperativo categórico kantiano: a pessoa se sente inapelavelmente obrigada a cumprir seu dever moral e, quando o transgride, sente-se profundamente culpada. Mas a experiência do imperativo categórico não provém, como em Kant, dos severos veredictos do tribunal da razão, para usar uma expressão de Deleuze (2004), mas dos veredictos - tão ou mais inapeláveis - de um outro tribunal: o do superego, instância psíquica inconsciente, nascida das lutas travadas no contexto do complexo de Édipo, e que Freud teorizou para dar conta, entre outras obrigações que os indivíduos colocam para si, daquelas oriundas da moralidade.

Analisemos, então, essa hipótese à luz dos binômios autonomia/heteronomia e universalismo/relativismo morais psicológicos.

Comecemos pela questão da autoridade. Ora, creio que, na teoria moral de Freud, ela não comparece ${ }^{3}$. Com efeito, antes de passar pelo complexo de Édipo, a criança obedeceria motivada pelo medo de punições ou de perder a proteção dos pais (Freud, 1929/1971), ou seja, não se trata de relação de autoridade, mas de poder, pelo menos se aceitarmos a definição de autoridade

3 Agradeço a minha colega Maria Thereza Costa Coelho de Souza, do Instituto de Psicologia da Universidade de São Paulo, pelas preciosas indicações que me deu a respeito dessa dimensão da obra de Freud. 
de Hannah Arendt (1972). A obediência é vista como prudência, e não como submissão voluntária a figuras de autoridade, segundo a interpretação de Piaget da moral heterônoma infantil. É por isso, aliás, que não há em Freud uma teoria do desenvolvimento moral propriamente dita - a criança passaria por apenas duas fases: uma pré-moral e, uma vez constituído o superego, outra, moral. Na fase pré-moral, não há relação de autoridade, e tampouco parece haver na fase de constituição do superego. Trata-se, mais uma vez, de um jogo de poder, pois há disputa de posições (filho, pai, mãe). E, se há interiorização dos interditos paternos, ela não provém do reconhecimento do pai como figura de autoridade, mas do reconhecimento de sua força. Em suma, creio que, no que tange à dimensão da autoridade, a teoria de Freud não implica heteronomia, o que poderia sugerir compatibilidade com as perspectivas teóricas de Piaget e Kohlberg.

Em compensação, a heteronomia me parece incontornável no que tange à liberdade, pelo fato de o superego ser uma instância inconsciente, que mais regula a consciência do que é regulada por ela. Como dizem Laplanche e Pontalis (1967), o acusador é um - o superego - e o acusado é outro - o ego. Este comparece perante um tribunal: ele é réu, e não juiz. Aliás, a radical inovação da teoria moral freudiana é justamente fazer comparecer forças inconscientes para explicar o fenômeno do dever. Em uma palavra, trata-se de uma teoria da heteronomia moral do homem, e, nesse ponto, inarticulável com as posições de Piaget e Kohlberg, assim como também o universalismo moral psicológico.

Haverá, segundo Freud, um conteúdo moral que tende a impor-se à consciência? Com exceção da proibição do incesto, não se identifica nenhum: os interditos interiorizados são os das figuras paternas, que são representantes, para a criança, da cultura. Se houver a possibilidade de a humanidade caminhar para um determinado sistema moral, ela deverá ser procurada do lado das leis sociológicas, e não psicológicas. Logo, o relativismo moral parece imporse: o sujeito assumirá a moral de sua cultura, seja ela qual for. Novamente, vejo absoluta incompatibilidade entre a teoria de Freud e as de Piaget e Kohlberg nesse ponto crucial.

Vamos, agora, abordar outra teoria que dá ênfase à dimensão afetiva da moralidade: a de Émile Durkheim (1974). 


\section{Desenvolvimento Humano: Contribuições da Psicologia Moral}

Como se sabe, Durkheim foi um dos primeiros a se debruçar cientificamente sobre o fenômeno da moralidade, notadamente motivado a defender a possibilidade de uma moral laica, rejeitada por quem não via com bons olhos a criação, por Jules Ferry, de uma escola pública, gratuita e para todos - e laica. Para a defesa dessa conquista democrática, Durkheim fez um trabalho de psicólogo, pois criou uma teoria por meio da qual procurou mostrar que não apenas a figura de Deus pode despertar e sustentar o dever moral. Essa teoria ainda tem ecos na Psicologia Moral, sobretudo entre os chamados culturalistas (ver Biaggio, 2002), que discordam das posições universalistas da corrente kohlberguiana.

Para Durkheim, o sentimento do dever é uma realidade humana - nesse ponto, converge com as demais teorias citadas até agora - e deve-se a um sentimento que ele chamou de sentimento do sagrado. Embora a referência ao sagrado possa ser interpretada como referência à religiosidade, Durkheim afirma que, se é verdade que a figura de Deus pode despertar tal sentimento, outro "ser" também tem esse potencial: o "ser coletivo", ou seja, a sociedade. Como se sabe, para Durkheim, o "ser coletivo" não equivale à soma de suas partes - os indivíduos. Muito pelo contrário, ele não só é dotado de leis próprias - que cabe à sociologia desvendar - como elas presidem os destinos dos indivíduos. O sentimento de obrigatoriedade pode ser despertado e desenvolvido justamente graças a essa relação inevitável de submissão da parte ao todo - logo, do indivíduo ao ser social -, acompanhada de um sentimento de desejabilidade: o indivíduo nada é por si só e ele retira sua riqueza individual daquelas presentes na cultura. Dito de outra forma, é porque o ser social pode inspirar a cada indivíduo, ao mesmo tempo, um sentimento de irremediável dependência e outro de desejabilidade, que se pode experimentar o sentimento do sagrado em relação a esse "ser coletivo". Digo que "pode inspirar" porque, para Durkheim, deve transcorrer todo um processo de educação moral para que o sentimento do sagrado se instale em cada criança.

Passemos, então, essa teoria pelos nossos crivos, começando pela questão da autonomia/heteronomia. Diferentemente de Freud, Durkheim não evoca forças inconscientes para explicar afetivamente o dever. Pode-se pensar a consciência como reguladora do sentimento do sagrado. Em compensação, se definirmos heteronomia não com referência à liberdade, mas em relação 
a figuras ou instâncias de autoridade, temos na teoria em tela a afirmação da necessidade da heteronomia para a moralidade humana. Ser moral é obedecer, diz Durkheim, e obedecer é obedecer aos mandamentos do "ser social". A autonomia consistiria não em assumir um poder legislador individual, mas na interpretação das leis morais oriundas de uma fonte transcendente. Nesse ponto, não parece haver articulação possível com as teorias de Piaget e Kohlberg. Ou melhor, há articulação possível - e o próprio Piaget a demonstrou -, mas apenas para as fases de heteronomia do desenvolvimento moral, e evidentemente não para a fase de autonomia.

E tampouco existe uma articulação quanto ao universalismo moral psicológico. Se porventura os homens caminharem para a legitimação universal de sistemas morais como o dos Direitos Humanos, será em razão de variáveis sociológicas, não psicológicas porque, para Durkheim, assim como para Freud, a fonte dos conteúdos morais é sempre exterior, não virtualmente interior, como para Piaget e Kohlberg.

Encerro esse tour d'horizon de teorias da afetividade comentando uma terceira, que não se pode atribuir a nenhum autor em particular, mas é evocada pela Psicologia Moral. Refiro-me àquelas - como as de Nancy Eisenberg (1979) ou de Hoffmann (1978) - que elegem a simpatia como afeto moral da maior importância. Como já falei nesse sentimento antes, podemos verificar imediatamente se ele é passível de articulação com as teorias do juízo moral.

Com relação à autonomia e à heteronomia, a simpatia não implica heteronomia, pois é regulada pela consciência. Como também independe de relações de autoridade, uma vez que não se experimenta simpatia em decorrência da obediência a figuras de autoridade, ela tampouco se relaciona à heteronomia. Pelo contrário, trata-se de um sentimento precoce, que faz com que outro ganhe saliência aos olhos da criança, e sem a mediação de figuras de autoridade (La Taille, 2006).

Quanto ao universalismo moral psicológico, a simpatia, por ser faculdade afetiva universal (todos os seres humanos são capazes de experimentá-la) e implicar condutas altruístas, também pode ser evocada por teorias com as de Piaget e Kohlberg. Mas há dois impedimentos para que se possa dizê-la representante da dimensão afetiva que falta a essas teorias. 


\section{Desenvolvimento Humano: Contribuições da Psicologia Moral}

Em primeiro lugar, a simpatia, por motivar condutas altruístas, articula-se mais com a generosidade do que com a justiça. Quando se é justo, age-se conforme regras e princípios bons para todos, ou seja, bons também para a própria pessoa que age com justiça. Em compensação, no ato generoso, dá-se a outrem o que lhe faz falta. Como diz Comte-Sponville (1995), a generosidade é um dom de si, uma forma de sacrifício - é, por conseguinte, uma virtude genuinamente altruísta. Nesse sentido, penso que a simpatia é antes fonte motivacional da generosidade do que da justiça.

Em segundo lugar, se é incontestável que a simpatia não raro motiva ações altruístas nos adultos e que ela participa do despertar do senso moral nas crianças pequenas, fazendo com que os outros ganhem saliência a seus olhos, há situações nas quais a ação moral acontece a despeito da ausência da simpatia. Pensemos, por exemplo, num médico que, por dever moral, cuida de pacientes cujos antecedentes tenebrosos certamente não lhe despertam simpatia: nesses casos, deve haver outra fonte motivacional para o dever. Em suma, a simpatia não parece ser a fonte motivacional universal das ações inspiradas pelo dever.

Chegamos ao final do primeiro passo desta exposição. Verificamos não haver real possibilidade de articulação entre as teorias da afetividade moral e as do juízo moral que escolhemos apresentar, assim como tampouco se encontra na simpatia uma fonte motivacional capaz de explicar todas as ações morais.

Então, fiquemos apenas com as teorias da afetividade. Mas essa escolha se "paga" de duas formas. A primeira é o abandono da autonomia moral possível e do universalismo moral psicológico. Sobretudo em relação à autonomia, penso que o preço seria caro demais. A segunda forma seria o desprezo pela quantidade de dados empíricos colhidos nos quatro cantos do mundo e que tendem a confirmar as teses de Piaget e Kohlberg.

Então, fiquemos apenas com as teorias do juízo moral. Mas, nesse caso, nos privaríamos de uma explicação da volição moral, que tais teorias não pretendem dar.

Assim, nenhuma das duas alternativas parece aceitável.

Então, sigamos em nossa reflexão, com um fato a meu ver essencial: as teorias morais que enfatizam a dimensão afetiva costumam apontar para uma fonte energética exclusivamente moral. E talvez isso seja uma séria limitação. 
Com efeito, a simpatia é sentimento essencialmente relacionado ao altruísmo. É um sentimento moral por excelência. O sentimento do sagrado, é claro, pode estar ligado à fé religiosa, e, para aqueles que não a têm, ele fica, na perspectiva de Durkheim, estritamente relacionado à moralidade. A culpa, sentimento que costuma ser associado à função do superego, também é essencialmente moral: pedem-se "desculpas" por uma transgressão, de maior ou menor gravidade. Falta falar do superego, essa instância psíquica identificada para explicar o controle moral das ações. Mas, no caso do superego, temos um fato interessante.

Como se sabe, Freud (1923/1991) batizou essa instância com dois nomes: superego e ideal de ego. Dois nomes para uma só função? Conheço os debates que se travam no seio das teorias psicanalíticas a respeito das possíveis diferenças entre superego e ideal de ego, mas, não sendo especialista na matéria, evito-os. Não vou enveredar pelas trilhas da psicanálise, mas vou usar a idéia - a idéia, não o conceito - da existência de um ideal de ego para verificar se ela não nos dá pistas que vale a pena seguir. Para tanto, vou pensar em três elementos que nos sugere a idéia de ideal de ego.

O primeiro é da busca da excelência, da excelência do ser. Ora, tal idéia não é estranha à Filosofia Moral, sobretudo no que diz respeito às abordagens que enfatizam a questão da felicidade. Encontramo-la, por exemplo, em Aristóteles (1965), cujo eudemonismo se traduz pelo cultivo das virtudes, formas de excelência do caráter. Encontramo-la também em Spinoza (1954), para quem o próprio do homem é passar de uma perfeição menor para uma perfeição maior. Encontramo-la ainda em Nietzsche (1995), que vê na vontade de potência a aspiração primeira dos homens, e também em Kant (1985), para quem o aperfeiçoamento próprio é condição necessária ao agir por dever. Em suma, a idéia de excelência, sugerida pela referência a um "ideal de ego", embora pouco pensada nas teorias da Psicologia Moral, está presente em alguns sistemas éticos. Note-se aqui que as noções de excelência, virtudes e felicidade têm voltado a ser valorizadas e estudadas por autores recentes, como MacIntyre (1981), que nos fala em virtudes, como Paul Ricoeur (1990), que define moral como esfera dos deveres e ética como esfera da felicidade, $\mathrm{e}$ como Taylor (1998), que relaciona o Eu e a moral, para dar alguns exemplos. 


\section{Desenvolvimento Humano: Contribuições da Psicologia Moral}

O segundo elemento sugerido pela idéia de ideal de ego é o do amor próprio. Com efeito, o superego, como sede dos interditos sociais, remete essencialmente às ações que devem ser feitas em relação a outrem, ações de que a cultura, ou a comunidade humana, precisa para sobreviver. Não é o próprio sujeito que está em jogo, mas as outras pessoas. Em compensação, a própria expressão "ideal de ego" coloca o ego no centro das preocupações - sugere mais um "amor de si" do que o amor de outrem. Ora, assim como acontece com a excelência, o amor próprio, embora em geral desconsiderado pelas teorias da Psicologia Moral, também foi e é alvo de análise na Filosofia Moral. Por alguns, é considerado grande adversário da moral, como pecado (orgulho), ou como cruel empecilho para o exercício da humildade, sem o qual a obediência às normas morais seria impossível. "O eu é odioso", afirmava Pascal (1670/1972), ilustre representante dessa posição crítica ao amor próprio, em geral presente nas éticas cristãs. Mas nem todos concordam. Para Rousseau (1966), por exemplo, o amor de si é condição necessária para o amor da humanidade. Paul Ricoeur (1990) nos diz que em todo desejo, portanto também naqueles que visam o bem de outras pessoas, há o deleite de si mesmo. E Fernando Savater defende sua necessária presença no agir moral, chegando a intitular um livro seu de Ética como amor-próprio (Savater, 2000). Em suma, o amor próprio é outro tema presente nas reflexões morais.

O terceiro e último elemento que nos sugere a idéia de ideal de ego é o sentimento de vergonha. Como veremos melhor a seguir, o sentimento de vergonha está intimamente associado à moralidade. No âmbito da própria psicanálise, Tisseron (1992), no seu estudo sobre esse sentimento, associa-o claramente ao ideal de ego (e associa culpa ao superego).

Em resumo, a idéia de ideal de ego não só nos sugere elementos outros que os tradicionalmente evocados pela Psicologia Moral, como nos remete a dimensões humanas outras que as estritamente morais. Por exemplo, a excelência do ser tanto pode ser valorizada pela moral (é o caso da pessoa que tem a virtude de ser justa) como pode ser-lhe estranha (por exemplo, ser um grande esportista). E vale o mesmo para o amor próprio, que pode incidir sobre virtudes morais ou sobre outros conteúdos. E também para a vergonha que, como logo veremos, pode ser moral ou não. 
Assim, podemos pensar que, ao seguir as pistas que a idéia de ideal de ego nos sugeriu, relacionamos moralidade e outras dimensões do desenvolvimento humano, para - não o esqueçamos - equacionar a questão da volição moral.

\section{Vergonha e honra}

Dos três elementos sugeridos pela "pista" ideal de ego, vou priorizar o sentimento de vergonha. Comecemos por defini-lo.

Trata-se de um desconforto psíquico, às vezes até insuportável, decorrente de dois tipos de situação - a exposição e o juízo negativo. A vergonha de exposição pode ser experimentada pelo simples fato de se estar exposto ao olhar alheio. Por outro lado, a vergonha judicativa pressupõe um juízo negativo: por exemplo, vergonha de se achar feio, de ter cometido um gafe, de fracassar em alguma atividade etc. Aqui, só a vergonha judicativa nos interessa.

Se a vergonha que nos interessa decorre de um juízo negativo, cabe perguntar quem é o autor desse juízo? Os outros? Ou a própria pessoa que experimenta a vergonha? Não há dúvidas de que os julgamentos alheios podem despertar o sentimento de vergonha ou amplificar sua força, mas a condição necessária para que ocorra é o juízo negativo de quem a experimenta (La Taille, 2002). Quem sente vergonha julga negativamente a si próprio. É por isso, aliás, que se pode sentir vergonha sozinho. Mesmo quando a vergonha é despertada ou amplificada pelo juízo alheio, é preciso que o sujeito envergonhado tenha identificado esses juízos como seus; do contrário, experimentará outros sentimentos. Por exemplo, se se diz a alguém que seu trabalho é ruim, mas essa pessoa discorda absolutamente dessa crítica, poderá talvez experimentar indignação por ser criticada injustamente, ou tristeza por não ver reconhecido o seu trabalho, mas não vergonha. Se sentir vergonha, é que assumiu o juízo para si.

Visto que a vergonha pressupõe um autojuízo negativo, devemos nos perguntar sobre o que incide tal juízo. Ora, todos os autores que se debruçaram sobre esse sentimento concordam que o que está em jogo na vergonha é o Eu (ver La Taille, 2002). Alguns até vêm nele uma diferença importante em rela- 


\section{Desenvolvimento Humano: Contribuições da Psicologia Moral}

ção à culpa, que incidiria sobre as ações. "O que eu fiz?" é a pergunta de quem se sente culpado. "O que eu fiz?", a do envergonhado. É claro que a vergonha pode ser desencadeada por ações, mas mesmo nesse caso é o Eu que está sub judice, assim como quando se experimenta a vergonha em razão de estados (ser pobre, por exemplo). Em todos os casos, é o Eu que é desvalorizado, e a pergunta do envergonhado é "quem sou eu?" Vê-se que é o amor próprio que está em jogo na vergonha.

Posto que a vergonha judicativa implica um juízo que incide sobre o Eu, devemos perguntar qual é a medida desse juízo. Trata-se de um juízo negativo em relação a quê?

A medida é que a que Elizabeth Harkot-de-La-Taille (1999), em seu estudo semiótico sobre a vergonha, chamou de "boa imagem". Experimentar a vergonha é julgar-se, de fato ou virtualmente, disjunto com relação à imagem de si valorizada - daí a expressão "boa imagem" -, a que se pensava corresponder ou à qual se pretende corresponder. Dito de outra forma, a vergonha decorre da distância que separa o ser do que ele idealiza ser. E reencontramos aqui a idéia de "ideal de si". Mas é preciso ir além na conceituação de Harkot-de-La-Taille. Duas situações podem ocorrer. Na primeira, o sujeito experimenta a vergonha no momento ou na lembrança de uma situação em que se julgou disjunto de sua "boa imagem". Trata-se de vergonha retrospectiva. Por exemplo, o sujeito sente vergonha ao tomar consciência de que está sendo indelicado ou quando se lembra de uma ocasião em que isso aconteceu. $\mathrm{Na}$ outra situação, o sujeito antecipa a vergonha que necessariamente experimentaria se acontecesse determinada situação. Nesse caso, para não ficar disjunto da boa imagem - ou para não se afastar muito dela -, o sujeito age para preservá-la. Trata-se da vergonha prospectiva. Por exemplo, o sujeito controla sua vontade de ser violento, antecipando a vergonha que sentiria se cedesse a seus impulsos. "Tenho vergonha só de pensar em fazer tal coisa" - eis a frase que expressa a vergonha prospectiva. Note-se que cada pessoa pode ter várias "boas imagens" a que gostaria de corresponder. O sentimento de vergonha parece atestar que cada um procura ver a si próprio como pessoa de valor, e que a tomada de consciência de que se está aquém desse valor, que julga ser seu (vergonha retrospectiva) ou de que se pode estar aquém (vergonha prospectiva) gera ou antecipa um desconforto psíquico. 
Todavia, podemos nos perguntar a respeito da motivação básica que leva os seres humanos a quererem ver a si próprios como pessoas de valor, $\mathrm{e}$ que gera dor psíquica quando ocorre o juízo de que tal valor inexiste ou deixou de existir. Ora, há na psicologia uma teoria que responde a isso. Refiro-me à de Alfred Adler (1991).

O célebre criador da Psicologia Individual cunhou os conceitos de complexo de inferioridade e complexo de superioridade, que passaram a ser de uso comum na linguagem leiga. Dizia ele que ser homem é sentir-se inferior, porque criou a hipótese de que cada um é movido pela procura de expansão de si próprio. Tal hipótese, antes também formulada por alguns filósofos, entre os quais Nietzsche (1995), implica que cada ser procura superar seus próprios limites, procura dar vazão à sua vontade de potência; procura, portanto, verse como pessoa de valor. Adler chega a falar em busca da perfeição e, assim, essa teoria implica também que a impossibilidade de êxito na expansão de si próprio gera desconforto psíquico.

Essa abordagem teórica é perfeitamente adequada para explicar o sentimento de vergonha. Com efeito, porque haveria "boas imagens" que todas as pessoas criam para si, senão em razão de uma busca de expansão de si próprios? Perguntado de outra maneira: por que as pessoas não se contentam com o que são? Ora, certamente porque há uma motivação forte, que as leva a criarem ideais de si, que são a tradução consciente dessa forma motivacional que pode permanecer inconsciente. Adler chega a dizer que a alma humana não se define pelo verbo "ser", mas pelo verbo "devir". E por que as pessoas sentiriam desconforto psíquico quando vêm disjuntas de tais boas imagens, senão porque tal diagnóstico de inferioridade traduz o fracasso da expansão de si, o fracasso, portanto, de darem vazão a uma fonte motivacional forte? Se uso aqui o adjetivo "forte", é porque a vergonha é, ela mesma, um sentimento forte, altamente indesejável, e que as pesquisas correlacionam com o suicídio, notadamente em jovens (ver Shreve \& Kunkel, 1991). Em suma, penso que a abordagem de Adler é boa para explicar a presença e a força do sentimento de vergonha.

No entanto, se opto por aceitar sua teoria a respeito da busca de expansão de si próprio e da forte dor psíquica causada pelo sentimento de inferioridade, não sigo suas idéias sobre um suposto "interesse social" universal e, logo, tampouco aceito seu diagnóstico de que os males do mundo - entre os 


\section{Desenvolvimento Humano: Contribuições da Psicologia Moral}

quais ele cita o alcoolismo, o suicídio, as guerras, a pena capital, o ódio racial, o crime e os comportamentos associais em geral - decorrem do sentimento de inferioridade. Que problemas como suicídio e alcoolismo, traduções de um mal-estar profundo, possam provir do fracasso na expansão de si tem todo o sentido, mas que condutas condenadas pela moral, como o ódio racial, os crimes, enfim, os comportamentos anti-sociais em geral tenham a mesma causa implica pensar que quem age contra a moral está necessariamente "de mal" consigo mesmo. Isso equivale a pensar que as "boas imagens" almejadas são sempre condizentes com a moral. A hipótese da tendência natural ao "interesse social" bastaria por si só para explicar, do ponto de vista afetivo, as ações morais, que só não aconteceriam em caso de fracasso na expansão de si. Creio poder fazer a economia da tese do interesse social que a história da humanidade parece desmentir, e ficar só com a da expansão de si que, como vimos, é coerente com a realidade do sentimento de vergonha.

Para tanto, é preciso sublinhar que as "boas imagens" podem associar-se aos mais diversos conteúdos e, logo, também a vergonha. Com efeito, alguém pode sentir vergonha porque valoriza a beleza para si e se vê como feio ou não bastante belo. Outro pode sentir vergonha de não jogar numa equipe de prestígio, porque se sente inferior pelo fato de jogar em pequenas equipes. Outro ainda poder sentir vergonha de ser pobre porque valoriza, para sua identidade, elementos de outras classes sociais. Finalmente, alguém pode sentir vergonha por ter traído um amigo, ter mentido ou cometido uma injustiça. Diferentemente dos anteriores, nestes últimos exemplos, trata-se de vergonha moral. É claro que pode acontecer que alguém sinta vergonha por todas essas razões, mas o importante é sublinhar o fato de que esse sentimento não incide necessariamente sobre valores morais.

Mais ainda: podem existir pessoas - e, de fato existem - que não sentem, ou sentem pouca vergonha por transgredir regras morais. Significativamente, a linguagem popular chama essas pessoas de "sem-vergonha", e aquelas que são morais, de pessoas que têm "vergonha na cara". E pode haver pessoas que não só não sentem vergonha de suas transgressões, mas até orgulho. Ser violento com outrem, por exemplo, pode ser a tradução da expansão de si, e não do contrário, como pensava Alder. Tudo é possível e depende da gênese da "boas imagens" eleitas por cada um. Voltarei a essa gênese no final. 
Antes, cumpre notar que a capacidade de sentir vergonha moral corresponde a um conceito moral clássico - a honra. Não é por acaso de que o clássico livro organizado por Peristiany (1965) intitula-se Honra e Vergonha.

Segundo Pitt-Rivers (1965), reconhecido estudioso do tema, existem dois tipos de honra: a honra-precedência, também chamada de honra exterior, e a honra-virtude, também chamada de honra interior. No primeiro tipo, o sujeito vê a si próprio como pessoa de valor - a honra incide sobre o amor próprio -, em razão não do que fez, mas de algum status que herdou. O exemplo clássico é a honra cavalheiresca, tão criticada por Schopenhauer (1989): tem-se honra porque se pertence a uma determinada classe social - no caso, a nobreza. Outras modalidades de status podem presidir à honra-precedência: por exemplo, o ser homem (no sentido gênero da palavra), o ser de alguma nacionalidade etc.

No caso da honra-precedência, não há nada necessariamente moral em sua origem. A moral - uma moral específica - comparece em defesa da honra. Se insultado por um igual, o nobre deve defender sua honra - notadamente com a morte ou a cruel humilhação do adversário. Se insultado ou humilhado seu país, o patriota sente-se obrigado a defender a honra de seu povo. E assim por diante. Digo que se trata de uma moral específica porque incide sobre um conteúdo específico: a defesa da honra.

No caso da honra-virtude, o lugar da moral é outro. A honra-virtude, ou interior, como o próprio nome indica, depende não do status do sujeito, mas de suas ações e atitudes. Mas de que ações e atitudes se trata? Ora, de ações e atitudes morais. Elas podem se dever a várias virtudes - justiça, generosidade, coragem, lealdade, por exemplo -, mas são sempre morais. Valores associados ao $\mathrm{Eu}$ - como ser excelente esportista, ser belo, ser rico - não se associam a esse tipo de honra. Em poucas palavras, o amor próprio implicado pela honravirtude sempre incide sobre valores morais. Tem honra-virtude quem vê a si próprio como pessoa moral, e, logo, quem sente vergonha por não corresponder às virtudes morais.

A relação da honra-virtude com a vergonha é clara. No caso da vergonha retrospectiva, a pessoa se sente envergonhada, privada de sua honra por ter agido contra a moral. Pode acontecer com qualquer um, a não ser que seja santo. No caso da vergonha prospectiva, a pessoa antecipa a vergonha, a desonra que forçosamente ocorreria, se agisse contra valores morais. 


\section{Desenvolvimento Humano: Contribuições da Psicologia Moral}

Às vezes, pode acontecer de a vergonha moral prospectiva ser incontornável, como no dilema em que se vê o inspetor Javert, do famoso romance Les Misérables, de Victor Hugo (1985): se não prender Jean Vallejean, que ele sabe ser um presidiário foragido, será inevitável a vergonha moral por ter falhado no cumprimento de seu dever de policial; se o prender, será igualmente inevitável a vergonha moral por levar às grades um homem que lhe salvou a vida (deslealdade ou ingratidão). Diante da impossibilidade de não sentir vergonha moral, de não perder sua honra, Javert se suicida.

Acabo de dar um exemplo que ilustra a relação entre vergonha e moral e, portanto, da relação entre honra e moral. Trago agora outro, tirado da realidade, em que se opõem vergonhas associadas a conteúdos diferentes - uma não moral, outra moral. Trata-se de um evento ocorrido com um notável escritor franco-argelino cuja vida testemunhou a grande importância que atribuía à moral. Refiro-me a Albert Camus.

No seu livro Le Premier Homme (Camus, 1994), em que narra sua própria história por meio da personagem Jacques, Camus nos conta que vivia em Alger - então colônia francesa -, que era órfão (perdeu o pai durante a I Guerra Mundial) e que foi criado pela mãe, pessoa pobre e de pouquíssima cultura. Vivamente incentivado por seu professor do primário, obteve êxito no exame de ingresso ao ginásio (Enseignement Secondaire), que, grosso modo, correspondia ao antigo exame de admissão brasileiro. Naquela época, era raro que crianças de famílias pobres tivessem acesso aos Lycées, fosse porque deviam urgentemente trabalhar para ajudar a família, fosse porque malogravam no referido exame. Ao ingressar no Liceu, o pequeno Camus viu-se menino pobre entre meninos de classes mais abastadas.

Num dos primeiros dias de aula, teve que preencher um formulário em que se pedia, ente outras coisas, a profissão da mãe. Ele escreveu "empregada doméstica" (domestique) - o que de fato ela era-e conta ele que, ao fazê-lo, sentiu vergonha. A história continua, mas comecemos por analisar esse momento do relato.

Ele sente vergonha. O que isso revela? Se as análises que se fizeram aqui desse sentimento forem corretas, revela que, entre as boas imagens a que pensa corresponder ou persegue, há algumas contraditórias com ser pobre, filho de uma família inculta. Essa condição fere seu amor próprio, se não, não se compreenderia por que experimenta a vergonha. 
Mas imediatamente aparece outra vergonha, mais forte que a primeira. Diz Camus: "comecei a escrever a palavra 'empregada doméstica', parei e, súbito, conheci a vergonha e a vergonha por ter sentido vergonha" (p. 187). Conheceu a vergonha - de ser pobre - e a vergonha por ter tido vergonha, ou seja, a vergonha por desprezar sua família, sua mãe, por ser desleal em relação a ela e por ter talvez vislumbrado a vontade de mentir sobre sua origem familiar e assim negar a mãe, ser injusto com essa mulher que trabalha de sol a sol para sustentá-lo e educá-lo. Trata-se, portanto, de uma vergonha moral, mais forte que a anterior, e que o faz agir moralmente: ele entrega o formulário preenchido corretamente - não nega a mãe.

Na terminologia usada aqui, o pequeno Camus deu prova de que construía o sentimento da honra-virtude. Segundo uma abordagem teórica recente em Psicologia Moral, podemos dizer que o pequeno Camus construía um moral self (ver Blasi, 1993, 1995; Colby \& Damon, 1993). Sendo o self o conjunto de representações que cada um tem de si (Perron, 1991), podemos dizer que entre essas representações são centrais aquelas associadas a valores morais, e que elas têm, assim, maior poder de motivação para a ação. As análises que fiz da vergonha e da honra são coerentes com essa nova abordagem, embora seus autores não se refiram a esses conceitos.

E, segundo a conceituação de Paul Ricoeur (1990), que dedicou parte de seu livro Soi-même comme un autre à moral, podemos afirmar que o pequeno Camus já tinha os primeiros elementos de uma ética. Como vimos, Ricoeur reserva a palavra ética para falar da felicidade, da "vida boa", mas ele não aceita qualquer opção de vida boa para constituir uma ética. Para ele, a ética é a perspectiva de uma vida boa, para e com outrem, em instituições justas. A abordagem que apresentei aqui se inspira nessa definição. Afinal, a vida boa pressupõe, como quer Adler (1991), a possibilidade da expansão de si - portanto, a possibilidade de se ter amor próprio. Ricoeur também comenta esse fato, junto com outros autores da Filosofia, como Tugendhat (1998), mas, para merecer o nome de ética, a vida boa deve incorporar a moral (para e com outrem, em instituições justas). É o que parece ter acontecido como o pequeno Camus: sente mais vergonha de ser injusto do que de ser pobre. Não há vida boa para ele na violência contra os outros. Ele tem mais vergonha de ser injusto, ou até mesmo de pensar em ser injusto, do que de ser injustiçado. 


\section{Desenvolvimento Humano: Contribuições da Psicologia Moral}

\section{Conclusões}

Posso agora concluir, começando por lembrar a hipótese que me serviu de guia: a fonte energética do dever precisa ser procurada não só em sentimentos exclusivamente morais, mas também em sentimentos que desempenham um papel para o próprio desenvolvimento humano.

Ao seguir essa linha de raciocínio, elegi o sentimento de vergonha, que não se relaciona apenas a conteúdos morais, mas também a outros que lhe são estranhos e até contrários. Não se trata, portanto, de uma fonte afetiva exclusiva do dever, que, na pessoa moral, geraria uma volição mais forte do que outras fontes. Trata-se, na verdade, de um jogo de forças no interior de um mesmo lócus: se valores morais forem intimamente associados aos rumos que toma a expansão de si, o querer agir moral, o dever, portanto, será uma realidade.

Como se vê, o dever não é um querer absoluto, mas um querer mais forte que outros oriundos de uma mesma fonte energética: a busca de ver a si próprio como valor. Mas, naturalmente, pode ocorrer - e certamente não é raro - que o querer agir moralmente seja mais fraco do que outros porque o sentimento da própria honra-virtude é fraco, e que outros, como a busca da glória, por exemplo, são afetivamente mais investidos e dirigem a busca de expansão de si próprio. Isto posto, a hipótese da importância da vergonha moral, ou da honra-virtude, não implica afirmar que outros sentimentos, como simpatia e culpa, não desempenham papel importante para a moralidade. Não estou à busca de um princípio único.

Vejamos, agora, se a hipótese aqui defendida pode ser articulada com as teorias do juízo moral, retomando os binômios universalismo/relativismo moral psicológico e autonomia/heteronomia.

Quanto ao primeiro binômio, não vejo como o sentimento de vergonha moral poderia, por si só, jogar luzes sobre a tendência humana a eleger certos conteúdos morais em detrimento de outros. Tal tese é essencialmente baseada numa teoria cognitiva que lança mão de conceitos lógicos como a igualdade, a equidade e a reciprocidade.

Em compensação, creio que a hipótese aqui desenvolvida pode muito bem se articular com a virtual autonomia moral. É certo que a possibilidade da 
experiência da vergonha é, no início, fruto da exposição ao juízo alheio e que, portanto, os primeiros juízos que a criança faz de si são praticamente idênticos àqueles que as outras pessoas, sobretudo as figuras de autoridade, fazem delas. Pode haver, portanto, uma vergonha moral heterônoma, decorrente da aceitação e da interiorização de juízos alheios. Todavia, como se disse da simpatia, a vergonha, justamente por pressupor um juízo, pode ser regulada pela consciência e, por processos de descentração, o indivíduo pode se liberar dos juízos alheios, relativizá-los e construir os seus próprios. Assim, nada implica a vergonha ser experimentada sem que a razão interfira e nada implica também que a dependência em relação à autoridade esteja necessariamente presente. Se a busca da expansão de si próprio impõe-se ao sujeito por ser uma motivação básica, os rumos que essa expansão tomará podem ser escolhidos por uma consciência autônoma.

Falta retomarmos o tema gerador deste artigo, a saber, as contribuições da Psicologia Moral para o desenvolvimento humano. Creio haver demonstrado a relação entre processos ontogenéticos e a moralidade, uma vez que o sentimento de vergonha não interessa apenas a esta última.

Mas alguém poderá dizer que tratei mais das contribuições dos conhecimentos de desenvolvimento humano para a moralidade do que o contrário. Em parte, é verdade. Mas não nos esqueçamos da recíproca. Se for verdade que a moralidade não consiste numa competência humana isolada, se for correto afirmar que ela participa, ou pode participar da construção de si mesmo, estudá-la significa, sim, contribuir para o entendimento do ser humano como um todo.

Aceito isto, há, sim, contribuição das teorias de Psicologia Moral para o entendimento do desenvolvimento humano. 


\title{
Desenvolvimento Humano: Contribuições da Psicologia Moral
}

La Taille, Y. de (2006). Human development: Contributions of Moral Psychology. Psicologia USP, 18(1), 11-36.

\begin{abstract}
We shall try to evaluate the contributions that the knowledge accumulated by Moral Psychology has made to the understanding of human development with the purpose of sustaining the following thesis: the source of energy of moral duty must be sought not only among exclusively moral feelings, but also among those which play a role in human development as a whole. Our approach will be presented in three steps. Firstly, we shall analyze if there is any possibility of articulation between the theories which emphasise the affective dimension of morality (Freud and Durkheim) and those which stress the intellectual dimension of morality (Piaget and Kohlberg). In the second place, once the impossibility of such articulation is verified, we shall defend that shame, present in morality but also present in other dimensions of human development, is a necessary condition for the feeling of moral duty. Finally, we shall discuss if shame can be evoked as an essential source of energy in the theoretical approaches which emphasise the intellectual dimension of morality.
\end{abstract}

Index terms: Morality. Human development. Shame. Honor.

La Taille, Y. de (2006). Développement humain: contributions de la Psychologie Morale. Psicologia USP, 18(1), 11-36.

Résumé: Nous chercherons à évaluer les contribuitions des connaissances accumulées par la Psychologie Morale pour la compréhension du développement humain en vue de soutenir la thèse d'après laquelle la source énergétique du devoir moral doit être cherchée non seulement du côté des sentiments exclusivement moraux, mas aussi du côté de ceux qui jouent um rôle dans le développement humain dans son ensemble. Notre démarche théorique se fera en trois étapes. Nous commençerons par vérifier s'il est possible d'articuler entre elles des théorie qui nous parlent de la dimension affective de la morale (Freud et Durkheim) e celles que en soulignent la dimension intelectuelle (Piaget e Kohlberg). Une fois constatée l'impossibilité d'une telle articulation, nous soutiendrons que le sentiment de la honte, présent dans la morale et aussi dans d'autes 


\section{Yves de La Taille}

aspects du développement humain, correspond a une condition nécessaire du sentiment du devoir. Finalement, nous analiserons si la honte peut être evoquée comme la souce énergétique des théories qui soulignent la dimensoin inteletuelle de la morale.

Mots-clés: Moral. Dévelopement humain. Honte. Honeur.

\section{Referências}

Adler, A. (1991). Le sens de la vie. Paris: Payot.

Arendt, H. (1972). La crise de la culture. Paris: Gallimard.

Aristote. (1965). Ethique de Nicomade. Paris: Flamarion.

Blasi, A (1993). The development of identity: Some implications for moral functioning. In G. G. Noam \& E. Wren (Org.), The moral self (pp. 99-122). Cambridge: The Mit Press.

Blasi, A. (1995). Moral understanding and the moral personality: The process of moral integration. In Kurtines (Org.), Moral development: An introduction (pp. 229-254). London: Allyn and Bacon.

Camus, A. (1994). Le premier homme. Paris: Gallimard.

Colby, A., \& Damon, W. (1993). The uniting of self and morality in the development of extraordinary moral commitment. In G. G. Noam \& E. Wren (Org.), The moral self (pp. 149-174). Cambridge: The Mit Press.

Comte-Sponville, A. (1995). Petit traité des grandes vertus. Paris: PUF.

Comte-Sponville, A., \& Féry, L. (1998). La sagesse des modernes. Paris: Lafont.

Deleuze, G. (2004). L’abécédaire de Gilles Deleuze. Paris: Editionsmontparnasse.

Durkheim, E. (1974). L'education morale. Paris: PUF.

Eisenberg, N. (1979). Development of chidren's prosocial judgment. Developmental Psychology, 15(2), 129-137.

Flanagan, O. (1996). Psychologie morale et éthique. Paris: PUF.

Freud, S. (1971). Malaise dans la civilisation. Paris: PUF. (Trabalho original publicado em 1929)

Freud, S. (1991). Le moi et le ça. Paris: PUF. (Trabalho original publicado em 1923)

Gilligan, C. (1982). Uma voz diferente. Rio de Janeiro: Rosa dos Ventos. 


\section{Desenvolvimento Humano: Contribuições da Psicologia Moral}

Habermas, J. (1986). Morale et communication - conscience morale et activité communicationnelle. Paris: Editions du Cerf.

Harkot-de-La-Taille, E. (1999). Ensaio semiótico sobre a vergonha. São Paulo: Humanitas.

Hoffman, M. (1978). Desenvolvimento moral. In Carmichael (Org.), Psicologia da criança, socialização 2. São Paulo: EDUSP.

Hugo, V. (1985). Les misérables. Paris: Livre de Poche.

Kant, E. (1985). Métaphysique des moeurs, deuxième partie: doctrine des vertus. Paris: Vrin.

Kohlberg, L. (1981). Essays on moral development. San Francisco, CA: Harper \& Row.

Laplanche, J., \& Pontalis, J.-B. (1967). Vocabulaire de la psychanalise. Paris: PUF.

La Taille, Y., de. (2002). Vergonha, a ferida moral. Petrópolis, RJ: Vozes.

La Taille, Y., de. (2006). Moral e ética: dimensões intelectuais e afetivas. Porto Alegre: Artmed.

MascIntyre, A. (1981). After vertue: A study in moral theorie. London: University of Notre Dame Press.

Nietzsche. (1995). La volonté de puissance I. Paris: Gallimard.

Pascal. (1972). Pensées. Paris: Librairie Générale Française. (Trabalho original publicado em 1670)

Peristiany, J. G. (1965). Honra e vergonha. Lisboa: Fundação Capouste Gulbenkian.

Perron, R. (1991). Les représentations de soi. Toulouse: Privat.

Piaget, J. (1932). Le jugement moral chez l'enfant. Paris: PUF.

Pitt-Rivers, J. (1965). Honra e posição social. In J. G. Peristiany (Org.), Honra e vergonha (pp. 11-60). Lisboa: Fundação Capouste Gulbenkian.

Rawls, J. (1971). Théorie de la justice. Paris: Seuil.

Ricoeur, P. (1990). Soi-même comme un autre. Paris: Seuil.

Rousseau, J. J. (1966). Emile ou de l'éducation. Paris: Garnier-Flammarion.

Savater, F. (2000). Ética como amor-próprio. São Paulo: Martins Fontes.

Schopenhauer, A. (1989). Aphorismes sur la sagesse de la vie. Paris: PUF.

Shreve, B., \& Kunkel, M. (1991). Self-psychology, shame and adolescent suicide: theoretical and pratical considerations. Journal of Counseling and Development, 169, 305-311.

Smith, A. (1999). Théorie des sentiments moraux. Paris: PUF. 


\section{Yves de La Taille}

Spinoza. (1954). L'ethique. Paris: Gallimard. (Trabalho original publicado em 1677)

Taylor, C. (1998). Les sources du moi. Paris: Seuil.

Tisseron, S. (1992). La honte. Paris: Dunod.

Tugendhat, E. (1998). Conférences sur l'éthique. Paris: PUF.

Recebido em: 30/08/2006

Aceito em: 11/09/2006 